International Review of Research in Open and Distributed Learning Volume 16, Number 1

February - 2015

\title{
The Pixelated Professor: Faculty in Immersive Virtual Worlds
}

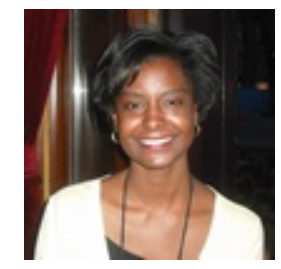

Stephanie Blackmon

\begin{abstract}
Online environments, particularly virtual worlds, can sometimes complicate issues of self expression. For example, the faculty member who loves punk rock has an opportunity, through hairstyle and attire choices in the virtual world, to share that part of herself with students. However, deciding to share that part of the self can depend on a number of factors: departmental guidelines, ideas of professionalism, privacy concerns, or the need for separation between the inclass self and the out-of-class self. In my study on faculty in virtual worlds, I examined faculty members' perspectives on recreating and being themselves in immersive virtual environments.
\end{abstract}

Keywords: Online learning; distance education; interactive learning environments; online teaching; pedagogical issues; higher education 


\section{Introduction}

\section{Growth in Online Education}

Online gaming and social networking have grown exponentially over the past few years, and their growth has permeated other areas as well, particularly higher education. Many students have come to expect the flexibility of online learning and the interactive components that games, social networks, and three dimensional virtual environments add to online courses. Twenty-first century students, according to Savin-Baden (2008), "are more mixed in age range, tend to be in employment whilst studying, learn on the move and have diverse expectations of what learning should be" (p. 151). One tool that combines the flexibility of online learning with the interactivity and increased technology some students have come to expect is the three dimensional virtual world, a topic I will expound upon in the following sections.

\section{Statement of the Problem}

As online educators pursue different platforms to deliver online courses, it is important to examine professors' experiences with these platforms. For example, more and more faculty use three dimensional virtual worlds to deliver online courses, so examining their experiences with that type of platform is an important endeavor.

Several researchers have investigated faculty members' experiences in three dimensional virtual worlds. For example, Dutton (2009) examined professors' overall experiences in the virtual world Second Life (SL), while Molka-Danielsen and Deutschmann (2009) created a guide for faculty in Second Life. According to Herold (2010), finding results about teaching and learning in Second Life is challenging. Furthermore, not many studies explore instructors' more specific experiences in the three dimensional virtual world, such as how faculty recreate themselves in a virtual environment like Second Life. Understanding these elements can inform the use of online classrooms and help improve professors' experiences in the online environment. Therefore, I conducted a study on faculty members' lived experiences in Second Life.

\section{Purpose}

The purpose of my qualitative study, as briefly noted in the Problem section, is to explore faculty members' lived experiences with recreating their faculty personae in the three dimensional virtual world classroom. I focused on a particular aspect of faculty members' experiences in a virtual world that has been used to deliver numerous online courses, Second Life. Second Life is certainly not the only three dimensional virtual world available for use. However, as noted earlier, several faculty are familiar with and use this environment if they are looking to use an immersive virtual

world for online classes. This study comes from a larger study I conducted on faculty persona in the virtual world, and its significance will be discussed in the following section.

This work is licensed under a Creative Commons Attribution 4.0 International License. 


\section{Significance}

My study is significant to faculty, administrators, researchers, or anyone with an interest in professors' experiences with expressing who they are in online environments. Other researchers can use information from my study to continue the discussion about faculty persona in Second Life and other three dimensional virtual environments. In their study that, in part, addressed faculty members' experiences with social networks online, Veletsianos and Kimmons (2013) suggested that too few studies have focused on faculty members' experiences using various technologies. My study seeks to expand the research offerings related to faculty members' experiences with technology.

\section{Review of the Literature}

\section{Persona and Online Educators}

Sometimes it can be challenging for faculty members to bring who they are in the real world into the digital environment. For example, in Baran, Correia, and Thompson's (2013) work on successful online teachers in higher education, faculty members highlighted the difficulty they had with integrating their personas into online environments. The "absence of nonverbal cues presented challenges" for those faculty members, so they were constantly looking for and trying various strategies to get to know students and allow students to get to know them (Baran et al., 2013). For other faculty members, their personae were limited in that they could not have the spontaneity in the online classroom that they had in the traditional classroom. One professor expressed, "You can't be extemporaneous with this [ALN] the way you can be...in the classroom" (Coppola, Hiltz, \& Rotter, 2002, p. 183). Out of 20 faculty participants, 17 of them indicated that they have to change their persona when teaching online (Coppola et al., 2002).

For other professors, theirs was an issue of formal versus informal persona. One faculty member noted, "I found myself having a completely different personality in [ALN], writing initially much more stilted things, more formal things" (Coppola et al. 2002, p. 182). These persona issues in traditional online environments are sometimes further complicated in three dimensional virtual worlds.

\section{Second Life Persona}

J ust as professors noted differences in their personae for traditional online environments, faculty members who use virtual worlds like Second Life expressed some differences as well. For example, a professor from Savin-Baden's (2010) study saw the Second Life medium as a chance to try something new. The professor interchanged male and female avatars often and also selected a name that could be seen as male or female. Other SL users have also adjusted elements of their real-world selves, even when supposedly recreating those versions of themselves in Second Life (Bullingham \& Vasconcelos, 2013), and other researchers have investigated what these issues of

This work is licensed under a $\underline{\text { Creative Commons Attribution } 4.0 \text { International License. }}$ 
representation suggest in Second Life (Bloustien \&Wood, 2013). However, some faculty members noted challenges with faculty persona in the immersive virtual world. For example, professor Sara Robbins indicated that "role markers" disappear in Second Life, shifting the classroom dynamics between professor and student (Livingstone \& Kemp, 2006, p. 37). She went on to state that the faculty member's loss of authority turned into student ownership.

In some cases, however, this shift in dynamics can be problematic. A professor from Dutton's (2009) study mentioned that when a professor takes on a different persona in the virtual world, students will sometimes ignore the professor because there is some confusion over who is "in charge."

What each of these instances addresses is the almost-inherent challenge of persona in online environments. Even when online teachers are seen as excelling in teaching their online courses, as the faculty members in Baran et al. (2013), persona transference from the face-to-face environment to the online environment can be challenging. Another layer of complexity is added when these personae are re-created in three dimensional virtual worlds like SL. For example, as Robbins (Livingstone \& Kemp, 2006) and the faculty member from Dutton's study (2009) pointed out, the animated nature of Second Life can complicate issues of authority and roles in the classroom. As faculty members continue to use environments like SL, it becomes increasingly important to address issues related to how faculty members create/recreate their personae in these types of environments, as my study does.

\section{Conceptual Framework}

The framework for my study is the concept of persona. The Oxford Dictionary of Literary Terms (Baldick, 2008) defined persona as follows:

The assumed identity or fictional 'I' (literally a 'mask') assumed by a writer in a literary work; thus the speaker in a lyric poem, or the narrator in a fictional narrative... Some theorists of narrative fiction have preferred to distinguish between the narrator and the persona, making the persona equivalent to the implied author.

The uncertainty of the "implied author" works well for the virtual world because virtual world participants can either use digital versions of themselves, avatars, to replicate who they are in real life or author new versions of themselves in this new environment. Their narratives of themselves could be autobiography, complete fiction, or a combination of reality and fiction. Implicitly, my study is rooted in the notion that the professor's digital representation in Second Life represents the persona, and persona serves as the vantage point for my study. Instead of investigating and discussing the findings from my study as multiple identities, I chose to explain faculty members'

This work is licensed under a Creative Commons Attribution 4.0 International License. 
virtual iterations of self as personae. That perspective frames the data.

\section{Research Methods}

\section{Research Approach and Research Question}

For my qualitative study, my research question was the following: What are faculty members' lived experiences with creating a faculty persona in Second Life?

\section{Research Inquiry}

In order to access and provide interpretations of participants' lived experiences, I conducted a hermeneutic phenomenology as described by van Manen (1990). In addition to methodological features, van Manen (1990) also noted that hermeneutic phenomenology does not provide a theory for explaining or controlling the world, but the method helps us come into "more direct contact with the world" (p. 9). Therefore, when exploring the phenomenon of faculty constructing the faculty persona in a three dimensional virtual world, I did so with the understanding that I could not provide a full description of this human experience but only an opportunity to come into closer contact with the phenomenon.

\section{Participants}

I interviewed 10 participants from colleges and universities across the United States and around the world. Once the Institutional Review Board (IRB) approved my study, I found 10 participants who had either taught part of a fully-online course in Second Life or who had taught a course completely in Second Life. I found participants by reviewing literature on Second Life that I collected from outlets like The Chronicle of Higher Education, EBSCO, Google Scholar, a university library's search tool, and ERIC. I selected participants who wrote the articles about their experiences teaching in Second Life or who were mentioned in articles about teaching in Second Life, recorded their contact information, and emailed them about participating in my study. My potential participant pool was not limited based on number of online classes taught, tenure status, choice to teach online, years at an institution, or institution type (college, university, or community college). The 10 participants for my study were from four-year colleges and universities from around the world. The full list of participants is as follows:

Participant 1-Frank: Department chair and university professor; southeastern U. S. university with at least 5,000 students; 10 years teaching at current institution; began teaching in SL in 2006 and has taught more courses than he can remember

Participant 2-Greg: Associate professor; western U. S. undergraduate university with 3 or 4,000 students; six years at current institution; taught one online course completely online using SL as part of the course

This work is licensed under a Creative Commons Attribution 4.0 International License. 
Participant 3-Ian: Associate professor; university in the southwestern U. S.; also taught at a university in the midwestern U. S. with around 13,000 students; 14 years at midwestern institution; taught over 40 sections of a course in SL and has taught in SL for seven years

Participant 4-Carla: Associate professor; doctoral institution in the southeastern U. S.; nine years at current institution; taught one class in Second Life for several semesters

Participant 5-Eva: Full professor; doctoral institution in the southeastern U. S.; 30 years at current institution; taught two classes for the past two years with the traditional online format and SL

Participant 6-John: Senior research fellow; United Kingdom (UK) university; four years at current institution and seven years at a previous UK university; taught at least five courses completely in SL for several European universities

Participant 7-Martin: Senior lecturer; Australian distance university, mid-ranked; eight years at current institution; taught two classes in SL twice

Participant 8-Adam: Junior lecturer; university in southeastern Sweden; about 12 years at current institution; taught two courses in SL, with multiple sections of one course

Participant 9-Emma: Research fellow; UK distance learning university; four years at current institution; taught SL section of one course

Participant 10-Mel: Clinical assistant professor; midwestern U. S. comprehensive public university; eight years at current institution; taught three online classes using SL for some parts of the classes for one year

\section{Data Collection}

I conducted 30-minute to one-hour semi-structured online interviews in Second Life, and conducting the interviews in that environment allowed me to interact with faculty in the environment where they create their virtual world personae. Although van Manen (1990) emphasized the importance of asking questions aloud instead of in writing, as writing may allow participants to become more removed from the lived experience, online chats can often mimic the spontaneous nature of face-to-face conversations. Also, the idea of interviewing faculty members in the environment where they recreate their faculty personae has a number of advantages. For example, I was able to access a wider pool of participants (national as well as international), and I gained a greater sense of the benefits and challenges of virtual world personae as the participants described those benefits and challenges. Faculty members and students who interact in these environments cannot rely on traditional cues, and it is incumbent upon researchers to exercise new ways of accessing and articulating these differences as faculty and students experience them. In my original study, I conducted three interviews with each participant. The data I collected specifically regarding the way faculty construct their personae in the virtual world came from the

This work is licensed under a Creative Commons Attribution 4.0 International License. 
three sets of questions in my original study. The first set of questions dealt with persona in general (faculty members' definition and understanding of persona), the second set of questions focused on persona construction, and the third set of questions dealt with persona interaction.

\section{Confidentiality}

To ensure confidentiality, I gave all participants a pseudonym, although their SL comments are associated with their avatar names. Also, I did not name participants' universities or ask questions that could negatively affect their jobs.

\section{Data Analysis}

I used qualitative coding to analyze the data and ascertain the various "structures of experience" (van Manen, 1990). I isolated the themes as van Manen suggested: "the wholistic or sententious approach, the selective or highlighting approach, and the detailed or line-by-line approach" ( $\mathrm{p}$. 93). Using these approaches allowed me to explore the meaning of the entire text as well as select certain sections of the data and isolate themes.

\section{Quality Assurance}

Because my SL chat room interviews with participants were available in their SL accounts and my account, I did not have to transcribe the interviews or conduct member checks. Hermeneutic phenomenologies focus on lived experience, so I employed faculty/ peer debriefing to determine if participants' lived experiences were accessible. My faculty/ peer debriefer is a professor with many years of teaching experience at the university level.

\section{Researcher Positionality}

I used Barker, Pistrang, and Elliott's (2002) and Savin-Baden and Major's (2012) phenomenological lens to view my study. According to Savin-Baden and Major (2012), phenomenological researchers should not only indicate how background and experience influence research, but also share participants' lived experiences with a phenomenon. Barker et al. (2002) noted that the phenomenological lens should provide an opportunity to understand participants' lifeworlds.' Although I know that researcher bias influences research, my goal was to learn from participants' lived experiences and not foist my perspectives on their experiences. I used a situationalist orientation, as I employed hermeneutic phenomenology because I thought that it was the best way to answer the research question, not because I am solely a phenomenological researcher.

This work is licensed under a Creative Commons Attribution 4.0 International License. 


\section{Findings}

\section{Virtual World/Real World Connections}

Some participants highlighted connections between the virtual world persona and the real world persona, and some noticed marked differences between who they are in the face-to-face classroom and who they are in the immersive virtual world.

\section{Similarities.}

Several participants mentioned the numerous similarities between their real world persona and virtual world persona. For example, Ian stated, "I dress very much the same and interact with my students in a very similar manner. My online or SL persona is simply an extension of me represented in a different environment." Ian noted that his persona, regardless of medium, is "very personable, professional, helpful and demonstrative of an academic..." (ellipsis in original). Greg said that his virtual world persona is, "similar to [his] real life persona." He added: "I try to make my classrooms conversational, meaning that I encourage students to talk and ask questions as much as possible...Most students are respectful of me but also feel comfortable interrupting me to ask questions" (Greg, Participant 2). When discussing her persona, Carla stated, "I honestly don't think I have any differences." She added, "I try to be consistent despite the environment. I work very hard at that" (Carla, Participant 4).

For these participants, the virtual world/real world symmetry was often purposely created and maintained.

\section{Differences.}

Although some participants noticed many similarities between the real world persona and the virtual world persona, other participants indicated several differences. These participants were equally committed to having students feel comfortable in all classroom environments, but some of them noted differences in their personal comfort levels in the virtual world. Emma stated, "See-here I am folding my arms again--I wouldn't do that in RL [real life]- put my arms up to separate me from others like that." She added:

In the traditional classroom, I clearly have a deep and wide knowledge base about every aspect of what I'm doing. That's not the same in SL--so my persona is not as confident and directive in SL as I might be in traditional face to face teaching.

For J ohn, however, the increased comfort in the virtual world positively influenced his faculty persona. He stated, "I think I'm more confident here [in Second Life]." John added: My persona...actually my identity...in SL is different from my real life in that it is more outgoing,

This work is licensed under a Creative Commons Attribution 4.0 International License. 
confident. I feel this is an environment where being a bit more...errm unconventional is ok" (J ohn, Participant 6, ellipses in original transcript). J ohn continued, "Plus this is my environment :-) I know what I'm doing here more than most." J ohn's increased confidence in the virtual world resulted in a more open, confident faculty persona.

\section{Virtual World/Traditional Online Connections}

Participants also noted connections between the traditional online environment and the three dimensional virtual environment. For this study, traditional online areas include social networking sites, email, Blackboard, chat rooms, Moodle, and the like. However, some participants indicated that the virtual world is a little more freeing. Eva expressed:

I think in SL my personality is more easily discerned-I can use my voice, my movements, my appearance to reflect who I am and what I am. In Blackboard or e-mail I have to use a more standard approach that doesn't allow my personality to carry me or my message.

Martin, a distance university professor, noted, "I am more engaged in SL than elsewhere-not a huge user of social networking (Facebook etc).... For some reason SL seemed to be more useful and appropriate to what I want to get out of the virtual world."

All of the participants were concerned about students' experiences in online classes, but the professors' comfortability with the virtual world often affected their faculty personae. Confidence and comfortability matter.

\section{Virtual World Persona: Benefits}

Participants mentioned two advantages to the virtual world persona: freedom and interaction. The freedom to change avatars or outfit an avatar with various accoutrements appealed to participants, even if they did not take advantage of the numerous options.

\section{Freedom.}

J ohn stated:

I think it [the virtual world] gives me more freedom...both personally and professionally. Personally it's allowed me to explore different aspects of my personality. Professionally the main reason is that it's brought me into contact with a lot of people whom I wouldn't have known otherwise.

Eva noted, "I can be someone I'm not--totally--and not be distracted by my own self. My avatar does my work--so I just control her--and she's really awesome-and not distracted by my infallibility." Mel expressed that the virtual world allows people to add characteristics that are not

This work is licensed under a Creative Commons Attribution 4.0 International License. 
evident in real life. She noted, 'You can be something you are not... tall, for instance. You can get a new skin, hair, whatever" (ellipsis in original).

For some professors, this environment also presented increased opportunities for interaction.

\section{Interaction.}

Some faculty indicated increased interaction between themselves and their students when conducting classes (or parts of classes) in the virtual world. For example, Martin said: "For DE [distance education] students especially I wanted to build more that sense of collegiality which you miss by having no classroom contact...and SL definitely helps with this" (ellipsis in the original). He added:

In this context, it [the virtual world persona] does enable you to do things not possible in the physical world-- i.e. meet the 'students.' But also of course it does provide opportunities to explore different ways of presenting material (and student assessment tasks) as well as the broader thing of checking out different worlds. (Martin, Participant 7)

Greg stated:

I have taken students on tours in SL (like we go see the Sistine Chapel). This is one of the big advantages of virtual environments; you can do things that are not possible to do in the real world. Or at least would be much more difficult.

\section{Doppelgängers and Deviations: The Question of Avatar Choice}

When choosing avatars, some participants wanted replicas of their real-world selves, and other participants wanted to deviate from their real-world selves.

\section{Doppelgängers.}

Many participants wanted their avatars to mimic who they are in real life. For example, Carla stated, "My avatar looks pretty much like me, hair, figure, etc." She continued, "I am very much a by the rules kind of gal, so I would never think of going against what is expected. I am very conservative in dress, so I suppose it carried over to my avatar" (Carla, Participant 4). Greg noted, "I made something that sort of looks like me." He continued, "Since my students know who I am in SL, I try to project the same image in SL as I would in the real world" (Greg, Participant 2). Eva expressed a similar sentiment stating, "I wanted to be blonde in SL--I am in my real life--and I wanted to have blue eyes--I do in real life!" Likewise, Adam created an avatar to resemble who he is in real life:

This work is licensed under a Creative Commons Attribution 4.0 International License. 
I just took one of the standard avatars available at the time and tweaked it a bit to make it look a bit more like what I look like IRL [in real life]. I keep getting offers from friends to take me shopping...but I'm a bit of a slob IRL too, so I didn't want a fancy avatar!

\section{Deviations.}

While some participants created avatars with their personalities and their real-life characteristics, other participants maintained their personalities but selected avatars who do not look the way the participants look in real life. Martin noted, "I hasten to add my avatar...is nothing like me!" However, Martin also stated that his avatar still possesses characteristics that he values in real life.

J ohn saw his avatar deviation as an opportunity to challenge norms. He stated, "I've tried to pick avatars that don't really reflect my ethnicity or sometimes species. They are all male though" (John, Participant 6). John continued, "I wanted to remove people's expectations about my ethnicity and didn't want to buy into one particular one." He also emphasized, "Some avatars I rejected because they would have caused too much offence." J ohn was careful to point out that although his avatar(s) may not have many of his real-life physical characteristics, they still have some of the personal characteristics he values:

...I think the important thing to help interactions is for the avatar to convey as much a sense of a person as possible so I have facial animations, I have an animation overrider to give me a normal walk, I use emoticons and so on and gestures. So even though it [my avatar] may not be entirely realistic...it gives some sense of a person at the other end.

All of the participants, the doppelgängers and the deviators, chose to maintain their personality characteristics no matter which avatar elements they chose.

\section{Material Messages}

Another very important element professors valued when recreating themselves in the virtual world was what I term material messages. The materials of the avatar, for example, clothes, skins, and movements, communicate the user's proficiency level. The way an avatar looks, and even the avatar's creation date, influence the way others perceive the avatar. Frank noted, "I shopped for premium skins, clothes, hair, shoes." He continued, "They [colleagues] know the brand names, the designers" (Frank, Participant 1).

This work is licensed under a Creative Commons Attribution 4.0 International License. 
J ohn noted:

I wanted to show I understood this medium, had adapted to it. So I wanted to get the animated walk and a proper skin and hair. I felt I needed to look accomplished...that was the image I wanted to project.

Emma made a similar observation, stating, "I also wanted an avatar who looked fairly competent, so I bought [my avatar] a skin and hair and poses." She continued, "I like to look as if I know what I'm doing in world, so I like to have a good quality skin and at least some animations" (Emma, Participant 9). As noted earlier, the look of the avatar communicates a message about the user's expertise. Eva and Adam added to that point. Eva stated,

..I'm somewhat intimidated when the other avatars are clearly more advanced than I am. I always check out their clothes, hair, and overall appearance, but more than that, there's an ease and familiarity with SL that some other 'adult' avatars have that I haven't developed yet. I feel a bit like an awkward teenager.

Adam said, "I've sometimes been looked down upon in some SL environments for not looking spectacular enough...but those are not opinions I pay much attention to."

\section{The Idea of Professionalism}

Participants also emphasized the importance of professionalism, even though a few of them differed on what professionalism in the virtual world looks like. Some made connections between avatar choice and professionalism while others made connections between proficiency in the virtual world and professionalism.

\section{Avatar choice.}

Both Carla and Ian saw avatar choice as being directly tied to professionalism. For example, Carla mentioned the importance of having a professional image, and when asked to expound on the term "professional image," she stated, "I think the term is all encompassing. We are expected to look like humans and dress in professional attire." Carla added, "...I always appear in human form and my appearance looks pretty much like I do in real life. I don't allow vampires or non-humans in my classroom (too distracting)." Ian also mentioned the importance of a professional image and noted the importance of "wanting [his] students not to be distracted by an unusual avatar, as opposed to someone/[an] avatar that is more representative of who [he is] in RL." When explaining the term "unusual avatar," Ian stated, "Well, I've seen colleagues of mine who have avatars of dragons, aliens, or some other inhuman or animalistic character. I did not want that and thought it would be more distracting, albeit entertaining."

This work is licensed under a Creative Commons Attribution 4.0 International License. 
Although most participants saw a human avatar as an integral part of professionalism, J ohn had a different perspective. His non-human avatar served as a way to challenge social norms and show his mastery of the virtual world. J ohn stated:

People who've come in [into Second Life] more recently go straight to being professional looking. I've not followed that trend I think because I resist that move towards conformity. And maybe my professorial image in the physical world is not so determined by peers anyway. (J ohn, Participant 6)

He continued, "I felt I needed to look accomplished...that was the image I wanted to project and that was where I saw my professionalism being not wearing something that looked normal, although that's also important I realise now." J ohn added, "But there's too much normal in the real world :-) don't want to bring it into here [virtual world]" (J ohn, Participant 6). Like the other participants, John valued professionalism, but he displayed his professionalism in a different way.

\section{Discussion}

As indicated in the data, faculty members' experiences with persona in the virtual world extend beyond merely selecting an avatar with no thought for the environment's other elements. Faculty members, even when they choose stock avatars, are quite deliberate about those decisions. They understand the messages that are communicated through the initial act of selecting an avatar. Professors also give thoughtful consideration to the learning tools and opportunities within the virtual environment, whether the lesson is to not make generalizations about competence based on avatar choice or a class field trip to another island. Each participant saw the virtual world as another way to connect with students, and that type of connection is not always present in traditional online environments. Contextually, faculty members' appreciation for the enhanced freedoms and interactions in the virtual world highlight some of the elements that are lacking in more static online environments. However, with the entree of video capabilities in traditional online courses, the avatar could be replaced by the real-time, real-life projection of professors and students. On the other hand, video capabilities cannot replicate the interactive tours that are available in the virtual world. These issues speak to the larger question of how to successfully interact and engage with students in the online environment. Virtual worlds are not without their challenges, but several faculty members find that these environments are still worthwhile. Virtual worlds allow students at a distance to create environments and practice certain skills that are either impossible or logistically challenging in the real world. Whether the virtual world is provided by Second Life, OpenSim, or some yet-to-be-discovered company in its incipience, there is a market for the enhanced interactions that three dimensional virtual worlds can provide.

This work is licensed under a Creative Commons Attribution 4.0 International License. 


\section{Additional Elements of Persona}

Participants from my study shared commonalities with professors in other online environments, particularly related to persona. In Avgerinou and Andersson's (2007) article on e-moderating and persona, they found that instructors engaged in e-moderating, or online teaching, were greatly concerned about their students' level of comfort with the course and online course environment. Professors in my study shared those sentiments. Every participant in my study, regardless of his or her own level of comfort in the virtual world classroom, was completely committed to having students feel comfortable in the virtual world course. Avgerinou and Andersson (2007) also indicated that the online instructors in their study sought to create "nurturing and friendly" classroom environments (p. 355). Likewise, professors in my study highlighted the importance of an environment where students felt free to ask questions. Paz Dennen (2007) also alluded to online course atmosphere and an instructor's persona in her study of positioning and persona, position as related to a professor's dominance or reticence in a course. The idea of positioning and persona did not come up in my study.

\section{Identity and Persona Revisited}

Participants' responses reified the decision to discuss persona and not identity. For each participant, the virtual world professorial self was an extension of the in-class self, and further still, an extension of the self in the traditional online environment. The identity is the allencompassing essence of a person, and the persona is an extension of the identity. When a participant, Carla, decided to dress her avatar in a holiday sweater, that was an extension of who she is in real life. She is also that person in a traditional online classroom, but traditional learning management systems do not afford professors or students opportunities to attire avatars. J ohn, as a person who enjoys experimenting with different looks and species, cannot do that in the face-toface environment. However, the importance of that expression is a part of a whole, and the virtual world allowed him to express the aspect and not the all-encompassing essence. Avgerinou and Andersson (2007) used the phrase "user representations" in their work on persona and emoderators (p. 356). Their idea of a representative seems tempting because of the avatars that are integral to three dimensional virtual worlds. These electronic emissaries are imbued with the knowledge and authority of the face-to-face version of the professor. However, my participants seemed to identify their avatars as extensions of themselves, which could connote a deeper relationship. The persona as expressed by the avatar is inextricably tied to the professor's identity. The avatar, in that case, is not just the representative or the proxy, but the person. Consider the emphasis on the avatar for participants in my study. Even when participants selected stock avatars, they did so with their face-to-face selves in mind.

The point of the persona is further extended by participants' remarks regarding the similarities and differences between their virtual world classrooms and traditional classrooms. As noted earlier, participants immediately indicated that who they were in virtual world classrooms mirrored who they were in traditional classrooms, an overt example of their personae. However, the differences in the virtual and traditional classrooms were also indicative of the persona. For

This work is licensed under a Creative Commons Attribution 4.0 International License. 
example, Eva noted that the technology of the virtual world classroom made her feel like a novice even though she is an expert in the content for her courses. Her decision to see a challenge as an opportunity speaks to another aspect of her persona that she was able to share with students in the virtual world classroom. The essence of who she is did not change, but the manifestation of that essence, her persona, was displayed in a different way because of the different environment. As with the e-moderators (Avgerinou \& Andersson, 2007), participants in my study valued the opportunities the online environment afforded and were committed to having their personae give some indication of their identities.

\section{Professionalism: A View from the Virtual}

Professors in my study overtly addressed the challenges and perspectives associated with professionalism in the virtual world. Similar perspectives are also present for faculty members who use more traditional social networking tools such as Facebook. For example, Veletsianos and Kimmons (2013) found that there is a delicate balance between the personal and professional for faculty members who use social networking sites; in that instance, participants used Facebook. While the professors appreciated both the personal and professional relationships cultivated through the social networking site, the apprehensions about the personal-professional balance were palpable (Veletsianos \& Kimmons, 2013). For participants in my study, however, the personal-professional distinctions were quite clear, but the definition of professionalism was different and led to a few challenges. Most of the participants viewed professionalism as related to clothing choices and a human avatar. However, John saw professionalism as related to the highest expression of virtual world acumen. The larger issue is really the question of whether or not the definition of professionalism should be changed, or at the very least extended. Is a nonhuman avatar a hindrance or an opportunity? John, the participant from my study who often employed non-human avatars, recognized and addressed the challenges associated with selecting a non-human avatar. However, the use of that non-human avatar also created an opportunity for students to learn not to judge people's intelligence based on their looks/ avatars. The virtual world provides numerous opportunities for exploration. The classroom could contain traditional desks and a board, or it could be situated among the clouds. Some would argue that the same experimentation should be allowed with avatars.

The other side of that scenario, however, is the question of limits. How far is too far? While the question of human or non-human avatar is a seemingly innocuous one, the "wrong" choice of avatar could prove offensive and detrimental to students. However, the "default" choice of a human avatar could mean that students may miss a chance to critically consider what it means to move and interact in an environment that is used both for playfulness and professional work.

\section{Implications}

As evidenced by my study and other literature concerning faculty and online environments, technology influences pedagogy. While that point may seem obvious outright, there are nuanced elements of that notion that may be missed. Participants in my study elucidated several of those nuanced points. For example, the choice to use an environment that allows avatars and 
teleportation is a pedagogical one. Further pedagogical choices include the type of avatar, the type of classroom (traditional desks or glowing orbs), the attire of the avatar (everything from jewelry to sunglasses), and the avatar's movements. As faculty and administrators continue to consider the types of online environments to use, these conversations about the connection between technology, pedagogy, and experiences with technology must continue as well. An institution's choice to adopt a particular learning management system, for example, is a decision about what faculty and students will or will not get in the classroom environment; it is a pedagogical decision. As institutions and individual faculty members continue to select these various technologies, it also becomes equally important to continue conducting research on faculty and students' experiences with these emerging technologies.

\section{Conclusion}

Many elements are involved in creating a faculty persona in the three dimensional virtual world. In order to understand some of those elements, it was important to gain access to professors' lived experiences with creating personae in the immersive virtual environment. While professors had different types of courses and teaching styles, they all seemed to focus on pedagogy over technology, student learning and comfortability, and professionalism. For other faculty members who want to venture into the virtual worlds or for those who are curious about others' experiences in the virtual environment, there is much to be gleaned from these participants' experiences. Although they taught/teach classes in Second Life, the insights from their lived experiences are useful when thinking about using any virtual world environment.

This work is licensed under a Creative Commons Attribution 4.0 International License. 


\section{References}

Avgerinou, M., \&Andersson, C. (2007). E-moderating personas. The Quarterly Review of Distance Education, 8(4), 353-364.

Baldick, C. (2008). Persona. In Oxford Dictionary of Literary Terms. Retrieved from http://lion.chadwyck.com.libdata.lib.ua.edu/searchFulltext.do?id=R04454244\&divLevel $=0$ \&queryId=../ session/ 1361769016 27579\&trailId =13C754362D6\&area=ref\&forward=c ritref_ft

Baran, E., Correia, A., \& Thompson, A. (2013). Tracing successful online teaching in higher education: Voices of exemplary online teachers. Teachers College Record, 115, 1-41.

Barker, C., Pistrang, N., \& Elliott, R. (2002). Research methods in clinical psychology: An introduction for students and practitioners ( $2^{\text {nd }}$ ed.). West Sussex, England: J ohn Wiley \& Sons.

Bloustien, G., \& Wood, D. (2013). Face, authenticity, transformations and aesthetics in Second Life. Body \& Society, 19(1), 52-81.

Bullingham, L., \&Vasconcelos, A. (2013). The presentation of self in the online world: Goffman and the study of online identities. J ournal of Information Science, 39(1), 101-112.

Coppola, N., Hiltz, S., \& Rotter, N. (2002). J ournal of Management Information Systems, 18(4), 169-189.

Dutton, C. (2009). Qualitative study of educator experiences in a virtual world. (Doctoral dissertation). Retrieved from Proquest, LLC.

Herold, D. (2010). Mediating media studies: Stimulating critical awareness in a virtual environment. Computers \& Education, 54, 791-798.

Livingstone, D., \& Kemp, J . (2006). Proceedings of the Second Life education workshop at the Second Life community convention. Retrieved from http:// www.simteach.com/ SLCC06/

Molka-Danielsen, J ., \&Deutschmann, M. (2009). Learning and teaching in the virtual world of Second Life. Trondheim, Norway: Tapir Academic Press.

Paz Dennen, V. (2007). Presence and positioning as components of online instructor persona. J ournal of Research on Technology in Education, 40(1), 95-108.

Savin-Baden, M. (2010). Changelings and shape shifters? Identity play and pedagogical positioning of staff in immersive virtual worlds. London Review of Education, 8(1), 2538.

This work is licensed under a Creative Commons Attribution 4.0 International License. 
Savin-Baden, M. (2008). From cognitive capability to social reform? Shifting perceptions of learning in immersive virtual worlds. Association for Learning Technology, 16(3),151161.

Savin-Baden, M., \& Major, C. (2012). Qualitative research: The essential guide to theory and practice. London, England: Routledge.

van Manen, M. (1990). Researching lived experience: Human science for an action sensitive pedagogy. Albany, NY: State University of New York Press.

Veletsianos, G., \& Kimmons, R. (2013). Scholars and faculty members' lived experiences in online social networks. Internet and Higher Education, 16, 43-50.

(C) Blackmon

\section{Athabasca University $\mathbf{a}$}

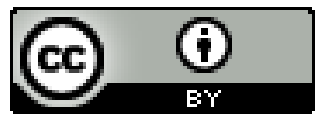

